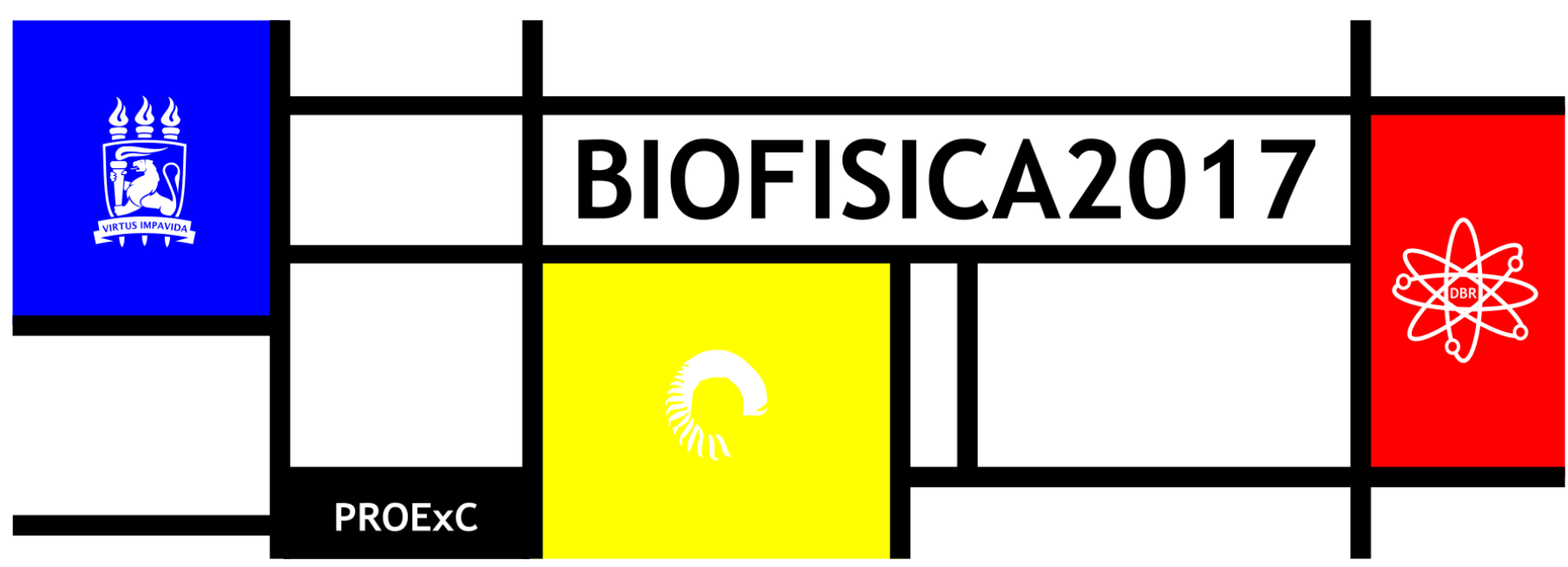

\title{
CARACTERIZAÇÃO DAS PRECIPITAÇÕES PARA DUAS REGIÕES FISIOGRÁFICAS DO ESTADO DE PERNAMBUCO
}

\author{
Rodolpho Souza Oliveira ${ }^{*}$, Thais Emanuelle Monteiro dos Santos Souza ${ }^{1}$ \\ ${ }^{1} \mathrm{UFPE}$ \\ *dophosouza@gmail.com
}

\begin{abstract}
INTRODUÇÃO
A precipitação pluvial tem sido bastante estudada em diferentes regiões do mundo, em face de sua importância no ciclo hidrológico e a manutenção dos seres vivos no planeta (Silva et al., 2011). Para Silva et al. (2007) as precipitações estão diretamente relacionadas aos mais diversos setores da sociedade, de forma que o regime pluviométrico afeta a economia, o meio ambiente e a sociedade.

Apresentando esse nível de relevância na vida de seres vivos e para o planeta, estudar, analisar e compreender as precipitações confere inúmeras vantagens, uma vez que as intercessões destes fenômenos na vida do homem estão cada vez mais notórias. Para Dourado Neto et al. (2005), o estudo das distribuições de variáveis climáticas no tempo, determinando seus padrões de ocorrência e permitindo a previsibilidade do comportamento climático de uma região, é uma ferramenta de grande valor para o planejamento e gestão de inúmeras atividades agropecuárias e humanas.

Pernambuco é um estado que fica localizado no Nordeste brasileiro, o clima é tropical de temperatura elevada a maior parte do ano. 0 Estado que além de ter uma configuração espacial dita como estreita e alongada, possui uma irregularidade no seu regime pluviográfico e está dividido em três zonas fisiográficas diferentes, são elas Zona da Mata, Agreste e Sertão.

A classificação das precipitações em conjunto com análises estatísticas permite esquematizar melhor os dados obtidos, de forma que ambas compreensão e explicação se tornem mais fáceis. Além de tornar possível identificar como funcionam os regimes pluviográficos da região.
\end{abstract}

\section{MATERIAIS E MÉTODOS}

Este estudo foi realizado utilizando dados de dois pluviógrafos cada um localizado em um município situado em duas zonas fisiográficas diferentes de Pernambuco. Sendo os municípios Recife e São Bento do Una.

O município de São Bento do Una localiza-se no Planalto da Borborema, à latitude $08^{\circ} 31^{\prime} 22^{\prime \prime}$ Sul e à longitude $36^{\circ} 26^{\prime} 40^{\prime \prime}$ Oeste, com altitude de 614 metros e se encontra na região fisiográfica conhecida como Agreste. A pluviosidade média anual é de $655 \mathrm{~mm}$ e a temperatura média de $23,8^{\circ} \mathrm{C}$ (FARIAS et al., 2000).
O município de Recife, a capital pernambucana, encontra-se localizado às coordenadas de latitude $8^{\circ} 04^{\prime} 03^{\prime \prime}$ Sul e $34^{\circ} 55^{\prime} 00^{\prime \prime}$ Oeste de longitude, com altitude de 4 metros e inserido na zona fisiográfica denominada como zona da mata. Recife apresenta uma pluviosidade média anual de $1804 \mathrm{~mm}$ e uma temperatura média anual em torno de $25,8{ }^{\circ} \mathrm{C}$. (Em: < http://pt.climatedata.org/location/5069/>

Para este trabalho os dados utilizados foram todos cedidos pela APAC (Agência Pernambucana de Água e Clima).

As informações obtidas de cada pluviógrafo são um compilado de dados de precipitações diárias para cada município, durante uma série de anos. Os dados de Recife se estendem do ano de 2000 até o ano de 2011, enquanto os dados de São Bento do Una se estendem de 2001 até o ano de 2011.

Para as análises dos dados foram utilizados os dados brutos obtidos pela APAC, não foram utilizados nenhum tipo de correção para quaisquer anos que apresentavam falhas no conjunto de dados. Os dados foram ordenados em planilhas no software Microsoft Office Excel, onde foram construídas planilhas para cada município.

Após a estruturação dos dados em ordem crescente, foram iniciados os cálculos de precipitação fragmentada $(\mathrm{mm})$ e a partir dos cálculos de precipitação fragmentada foram construídas as tabelas com somatórios das precipitações para cada mês de cada ano.

Posteriormente os dados de precipitações mensais foram utilizados para a construção de outra planilha onde constam todos os somatórios mensais para todos os anos. A partir daí foram evidenciados os valores mensais, anuais e os valores médios de precipitação. Utilizando estes dados foram construídos os gráficos de totais anuais e o de sazonalidade para cada município. Também foram evidenciados o total de dias estudados, os dias em que houve chuva e o percentual de chuvas para cada mês.

Foi realizada análise de frequência das precipitações, para isso foi utilizada a Regra de Sturges (Equação 01):

$K=1+3,3^{*} \log (n)$

Em que, $\mathrm{k}$ - número de classes, $\mathrm{n}$ - número de dados

Através dessa equação é possível classificar os dados, determinando um número ideal de intervalos de classes (CHIERICE \& LANDIM, 2013) e (MEDEIROS et al., 2013). 
Uma vez que o número de classes foi evidenciado calcula-se o intervalo de classes, ou largura de intervalo de classes (LIC), (Equação 02):

$\mathrm{LIC}=\mathrm{A} / \mathrm{K}$

Em que, A - amplitude entre os valores máximo e mínimo da amostra.

A partir dos elementos obtidos foram construídos os histogramas.

\section{RESULTADOS E DISCUSSÃO}

Analisando os totais anuais foi evidenciado que os anos mais chuvosos para o município de Recife foram 2005, 2006 e 2009 e consequentemente os anos de menores precipitações foram 2000, 2001 e 2007 (Gráfico 1).

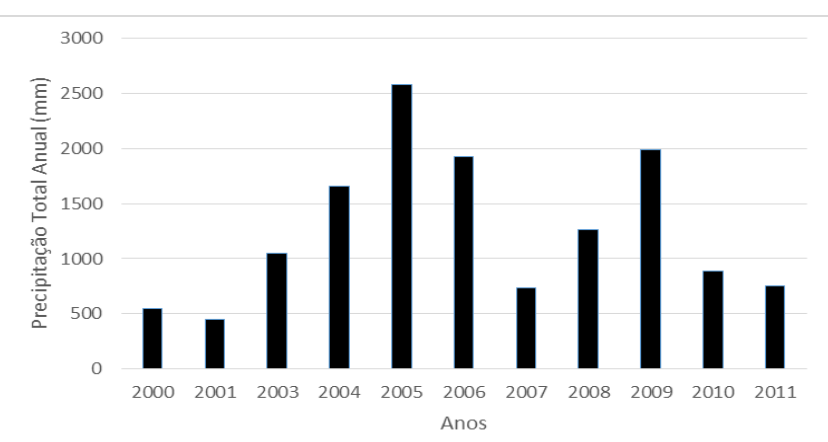

Gráfico 1. Totais Anuais para as precipitações de Recife ao longo dos anos estudados (Fonte: O Autor, 2016).

Para o município de São Bento do Una foi evidenciado que os anos mais chuvosos foram 2005, 2008 e 2010, respectivamente. Enquanto os anos onde houveram menores precipitações foram 2001, 2004 e 2009 (Gráfico 2).

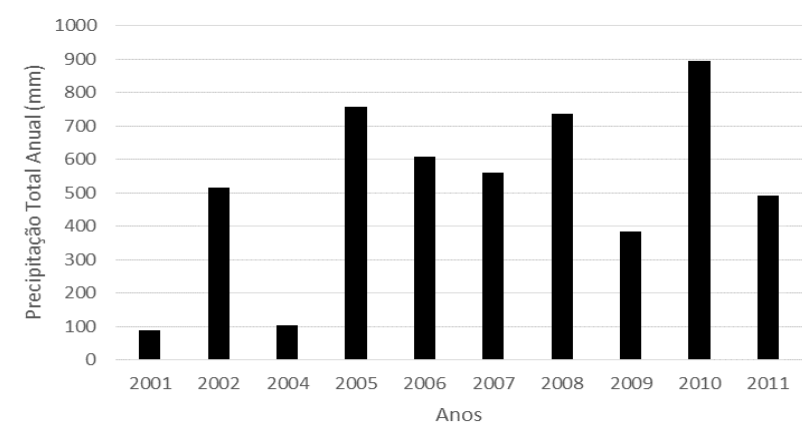

Gráfico 2. Totais Anuais para as precipitações de São Bento do Una ao longo dos anos estudados (Fonte: O Autor, 2016).

De acordo com Silva et al. (2011), a dificuldade da chegada das chuvas ao sertão se dá pelo Planalto da Borborema, devido a sua extensão do sul da Bahia até o Rio Grande do Norte. O Planalto da Borborema age como um obstáculo natural para as chuvas do Sertão. De acordo com o autor ao leste do Planalto, onde fica localizada a Zona da Mata, é mais úmido, enquanto que cada vez mais para o interior (Sertão e Agreste) o clima vai ficando mais seco (Figura 1).

Comparando o Gráfico 1 com o Gráficos 2 fica evidenciado o que foi elucidado por Lira et al. (2006) que na zona da mata as chuvas são em alta quantidade e muitas vezes acima das necessidades, quando comparadas às demais regiões fisiográficas de Pernambuco. A partir dos valores médios mensais e dos cálculos dos dias com chuva para cada mês, foi evidenciado que os meses mais chuvosos para o município de Recife de acordo com a porcentagem foram junho, julho e agosto com percentuais de $41 \%, 51 \%$ e $43 \%$ (Tabela 1).

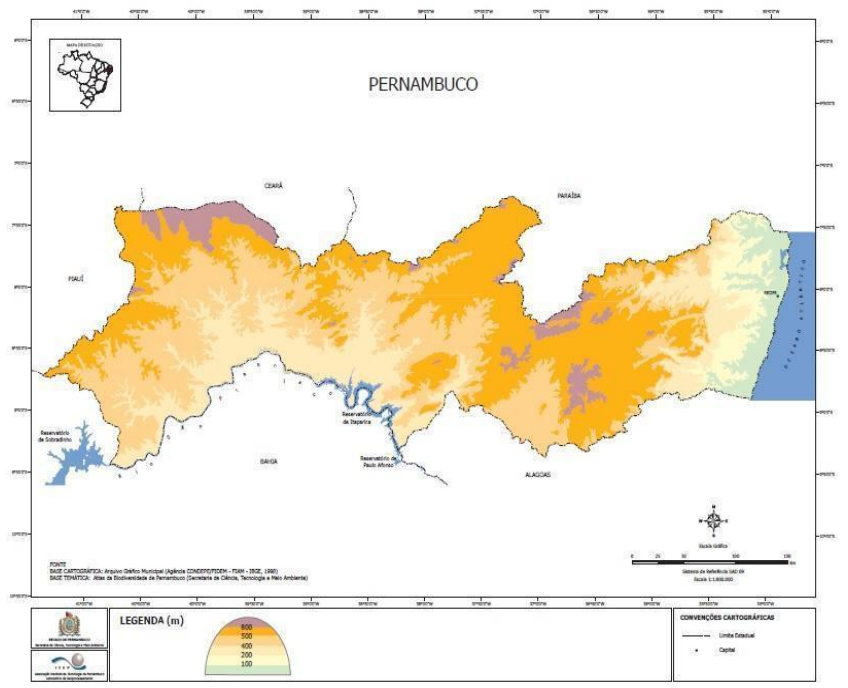

Figura 1. Mapa Hipsiométrico de Pernambuco destacando o Planalto da Borborema (Fonte: Secretaria de Recursos Hídricos e Energéticos - SRHE, 2016).

Tabela 1. Percentual de dias com chuva para a cidade do Recife.

\begin{tabular}{|c|c|c|c|c|}
\hline Meses & $\begin{array}{c}\text { Média } \\
\text { Mensal }\end{array}$ & $\begin{array}{c}\text { Total De Dias } \\
\text { Estudados }\end{array}$ & $\begin{array}{c}\text { Dias com } \\
\text { Chuva }\end{array}$ & Porcentagem \\
\hline Janeiro & 49 & 341 & 77 & $23 \%$ \\
\hline Fevereiro & 59 & 311 & 67 & $22 \%$ \\
\hline Março & 72 & 341 & 73 & $21 \%$ \\
\hline Abril & 158 & 330 & 104 & $32 \%$ \\
\hline Maio & 206 & 341 & 104 & $30 \%$ \\
\hline Junho & 262 & 330 & 134 & $41 \%$ \\
\hline Julho & 184 & 341 & 171 & $50 \%$ \\
\hline Agosto & 107 & 341 & 145 & $43 \%$ \\
\hline Setembro & 65 & 330 & 112 & $34 \%$ \\
\hline Outubro & 24 & 341 & 83 & $24 \%$ \\
\hline Novembro & 20 & 330 & 62 & $19 \%$ \\
\hline Dezembro & 54 & 341 & 64 & $19 \%$ \\
\hline
\end{tabular}

Para o município de São Bento do Uma, pode-se observar que de acordo com as porcentagens calculadas, os meses onde ocorreram maiores precipitações foram maio e junho, onde ficam evidenciados os percentuais de $40 \%$ e $45 \%$ para cada mês respectivamente de acordo com o resultado da porcentagem (Tabela 2).

Para o município de Recife é possível observar que o regime pluviográfico no município tende a ser maior entre os meses de abril a julho. Assim fica possível contestar que para o município de Recife os episódios de precipitações mais intensas tendem a ocorrer num período bem definido, no período chuvoso (marçoagosto) (Gráfico 3).

Seguindo a análise dos valores mensais para o município de São Bento do Una, o Gráfico 5 identifica que chuvas intensas ocorrem entre os meses de março e junho, da mesma forma, como o município de Recife, para São Bento do Una as precipitações mais altas ocorrem dentro do período chuvoso do Estado como pode ser observado no Gráfico 4. 
Tabela 2. Percentual de dias com chuva para a cidade de São Bento do Una.

\begin{tabular}{|c|c|c|c|c|}
\hline Meses & $\begin{array}{l}\text { Média } \\
\text { Mensal }\end{array}$ & $\begin{array}{c}\text { Total de Dias } \\
\text { Estudados }\end{array}$ & $\begin{array}{c}\text { Dias } \\
\text { com } \\
\text { Chuva }\end{array}$ & Porcentagem \\
\hline Janeiro & 32 & 310 & 58 & $19 \%$ \\
\hline Fevereiro & 43 & 282 & 73 & $26 \%$ \\
\hline Março & 86 & 310 & 78 & $25 \%$ \\
\hline Abril & 54 & 300 & 87 & $29 \%$ \\
\hline Maio & 80 & 310 & 125 & $40 \%$ \\
\hline Junho & 75 & 300 & 136 & $45 \%$ \\
\hline Julho & 24 & 310 & 103 & $33 \%$ \\
\hline Agosto & 20 & 310 & 102 & $33 \%$ \\
\hline Setembro & 13 & 300 & 68 & $23 \%$ \\
\hline Outubro & 16 & 310 & 45 & $15 \%$ \\
\hline Novembro & 5 & 300 & 28 & $9 \%$ \\
\hline Dezembro & 19 & 310 & 28 & $9 \%$ \\
\hline
\end{tabular}

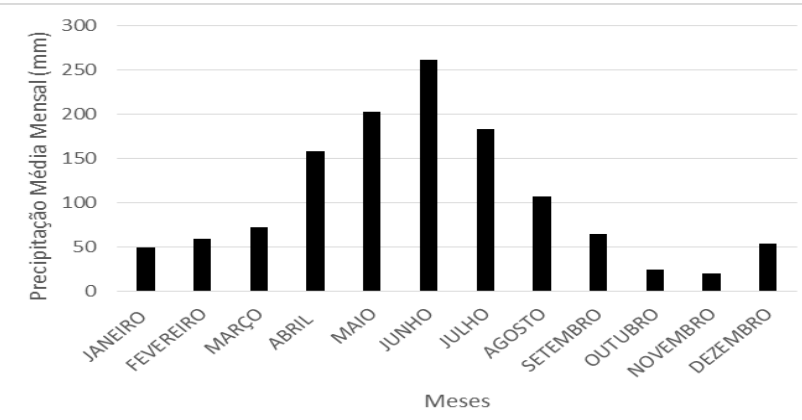

Gráfico 3. Sazonalidade da precipitação para a cidade de Recife (Fonte: O Autor, 2016).

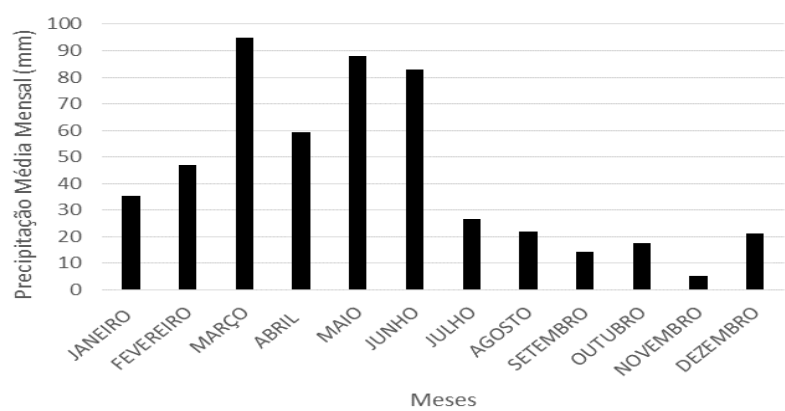

Gráfico 4. Sazonalidade da precipitação para a cidade de São Bento do Una (Fonte: 0 Autor, 2016).

Através das análises foi evidenciado que os episódios intensos de precipitação tendem a ocorrer em períodos semelhantes para os municípios. Abaixo, no Gráfico 5 , está representado um histograma com os dados de frequência relativa e absoluta da precipitação para o município de Recife.

Analisando um conjunto de dados do ano 2000 a 2011 fica evidenciado que o máximo de precipitação que ocorreu em Recife ao longo desses anos ficou entre 2050-2590 mm. Foi evidenciado que os episódios intensos de precipitação têm chances pequenas de ocorrer, segundo as análises as chances de ocorrerem precipitações anuais que ficam no intervalo de maior intensidade são menores, como pode ser observado no Gráfico 5 acima as chuvas de maior lâmina representam $10 \%$ das chuvas analisadas para o município de Recife nos anos estudados.

O Gráfico 6 abaixo apresenta o histograma para o município de São Bento do Una, onde após analisar as séries de anos ficou evidente que o máximo de precipitações para este município se encontra entre 700-910 mm anuais e que estes episódios de precipitações mais elevadas têm alta probabilidade de ocorrer no Agreste pernambucano, consequentemente.

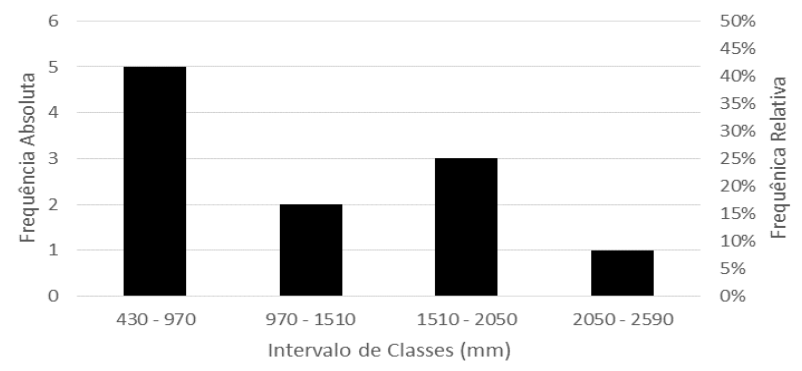

Gráfico 5. Histograma com os valores de precipitações anuais para o município de Recife Período de 2000 a 2011 ( Fonte: 0 Autor, 2016).

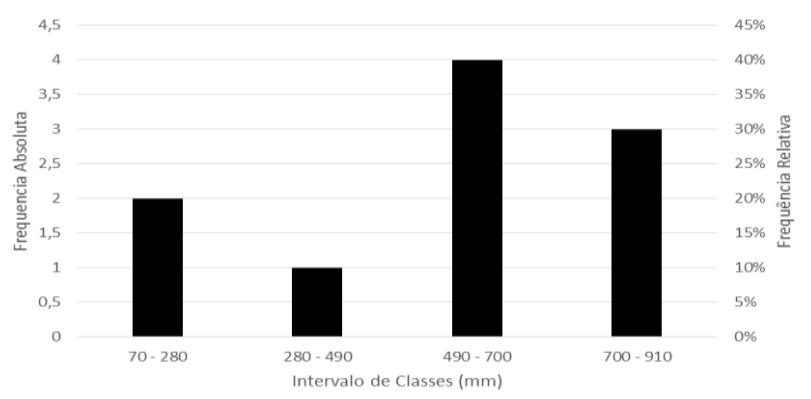

Gráfico 6. Histograma com os valores de precipitações anuais para o município de São Bento do Una - Período de 2000 a 2011 ( Fonte: 0 Autor, 2016).

Analisando os intervalos de classe e suas frequências, para este município as probabilidades de ocorrerem chuvas mais intensas são mais altas, quando comparado a Recife, São Bento do Una apresenta um regime de chuvas anuais de maior intensidade devido a probabilidade de ocorrências de chuvas mais intensas. As maiores ocorrências de precipitação se encontram no intervalo 490-700 mm de com uma ocorrência de $40 \%$ de acordo com os anos estudados, aqui já se pode notar as diferenças entre as chuvas entre os municípios anteriores.

Fazendo uma comparação com os histogramas anteriores observase o que foi apontado por Galvíncio e Moura (2005) que a irregularidade das chuvas é algo natural para a região que está inclusa no semiárido do Nordeste. Os autores ainda enfatizam que o problema comum de secas na Região Nordeste do Brasil está mais relacionado com a distribuição irregular das chuvas e não com sua falta. Outros fatores, tais como uma baixa capacidade de retenção de umidade no solo e altas taxas de evaporação e evapotranspiração, contribuem para agravar o problema.

\section{CONSIDERAÇÕES FINAIS}

Através das análises empregadas foi possível averiguar que as regiões possuem um regime pluviográfico bem semelhante e definido, no que se diz respeito a oscilação das chuvas. De modo que a maior parte das concentrações totais das chuvas, bem como os episódios de chuvas mais intensas, tendem a ocorrer nos períodos chuvosos do estado, que se estendem do mês de março ao mês de agosto;

Com relação a abundância de precipitações a Zona da Mata é onde se encontram os maiores totais anuais, seguida do Agreste.

O Agreste foi a região onde comumente foram apresentados episódios mais frequentes de precipitações de maior intensidade, ao contrário da Zona da Mata que apesar de apresentar um volume maior de chuvas, apresentam corriqueiramente chuvas de intensidade menor. 


\section{REFERÊNCIAS}

Climate-data.org. Clima: Recife. Disponível em: < http://pt.climate-data.org/location/5069/ > Acesso em: 10 de outubro de 2016.

DOURADO NETO, D.; ASSIS, J. P.; TIMM, L. C.; MANFRON, P. A.; SPAVORECK, G.; MARTIN, T. N. Ajustes de modelos de distribuição de probabilidade a séries históricas de precipitação pluvial em Piracicaba, SP. Revista Brasileira de Agrometeorologia, v. 13, n.2, p.273-283, 2005.

FARIAS, I., LIRA, M. D. A., SANTOS, D. D., TAVARES FILHO, J. J., SANTOS, M. D., Fernandes, A. P. M., \& SANTOS, V. D. Manejo de colheita e espaçamento da palma forrageira, em consórcio com sorgo granífero no Agreste de Pernambuco. Pesquisa Agropecuária Brasileira, Brasília, v.35, n.2, p.341-347. 2000.

GAVÍNCIO, J. D.; MOURA, M. S. B. Aspectos climáticos da captação de água de chuva no estado de Pernambuco. Revista de Geografia, Recife, v.22, N.2, 2005.

LIRA, V. M.; OLIVEIRA, F. M.; DANTAS, R. T.; SOUZA, W. M. Alterações da precipitação em municípios do estado de Pernambuco. Engenharia Ambiental, Espirito Santo do Pinhal, v.03, n.1, p. 052-061, jan/jun, 2006.

MEDEIROS, R. M.; SANTOS, D. C.; RAFAEL, A. R.; OLIVEIRA, V. G.; CORREIA, V. S.; BRITO, F. I. B. Frequência da precipitação pluvial no município de Bananeiras - PB. Resumos Expandidos do I CONICBIO / II CONABIO / VI SIMCBIO (v.2). Recife, 2013.

SILVA, J. C; HELDWEIN, A. B; MARTINS, F, B; TRENTIN, G; GRIMM, E. L. Análise de distribuição de chuva para Santa Maria, RS. Revista Brasileira de Engenharia Agrícola e Ambiental, Campina Grande, v.11, n.1, p.67-72, 2007.

SILVA, V. P. R.; PEREIRA, E. R. R.; AZEVEDO, P. V. SOUSA, F. A. S.; SOUSA, I. F. Análise da pluviometria e dias chuvosos na região nordeste do Brasil. Revista Brasileira de Engenharia Agrícola e Ambiental, Campina Grande, v.15, n.2, p.131-138, 2011.

CHIERICE, R. A. F.; LANDIM, P. M. B. Variabilidade espacial e temporal de precipitação pluviométrica na Bacia Hidrográfica do Rio Mogi Guaçu. Revista de Geociências. v. 33, n. 1, p.158-172, 2014. 